\title{
Kalkülüs Derslerinde Geogebra Fonksiyonlarından Nasıl Yararlanılabilir?
}

\author{
${ }^{1}$ Abdullah Özkale
}

\section{ÖZET}

Teknoloji destekli matematik eğitiminde farklı program ve aplikasyonların etkilerinin genişletilmesi perspektifinde bu çalışmada lisans/önlisans düzeyinde ele alınan kalkülüs dersleri için örnek etkinlikler ele alınmaktadır. Bu çalışmanın amacı kalkülüs dersleri için hazırlanacak GeoGebra ekinkilerinde öğreticilere yol göstermesi açısından enstrümantal orkestrasyon boyutlarına 1şık tutan tartışmalar sunmaktadır. Çalışmada kalkülüs eğitimi için GeoGebra programından nasıl yararlanılacağı ve etkinliklerin enstrümantal orkestrasyon türleri ile nasıl zenginleştirilebileceği üzerinde durulmaktadır. Çalışma kapsamında önerilen etkinlikler etkinlik tasarım parametreleri ve enstrümantal orkestrasyon türleri ile birlikte ele alınarak düzenlenmiştir. Özellikle COVID-19 Pandemi süreciyle birlikte uzaktan eğitim formatının genişleyen ağında öğrenenlerin ders ve çalışma motivasyonlarının teknoloji destekli etkinliklerle artırılması beklenmektedir. Uygulamalı ve mesleğe dönük yönü itibariyle kalkülüs derslerinde kullanılabilecek matematiksel simülasyonlarla ders süreçlerinin zenginleştirilebileceği ve öğrenenlerin kavramsal gelişimlerinin beslenebileceği, bu deneyimin gerçek hayat becerilerine yansitılabileceği düşünülmektedir.

Anahtar Kelimeler: GeoGebra, enstrümantal yaklaşım, kalkülüs, teknoloji destekli matematik eğitimi

\section{How Can Be Used Geogebra Functions In Calculus?}

\begin{abstract}
The study deals with sample tasks for calculus courses at the university level to expand the effects of different programs and applications in technology-supported mathematics education. The study aims to provide discussions that shed light on the dimensions of instrumental orchestration in terms of guiding the instructors in the GeoGebra tools to be prepared for the calculus. The study focuses on how to use the GeoGebra for calculus education and how the tasks can be enriched with instrumental orchestration types. The tasks within the study were organized by considering the task design parameters and instrumental orchestration types. It is expected that students' motivation to lessons and exercises will be increased with technology-supported activities, especially in the expanding network of distance education because of COVID-19 pandemic. It is thought that lessons can be enriched with mathematical simulations that can be used in calculus in terms of its applied and professional aspects. Also, the tasks can enrich the conceptual development of students and they can reflect this experience in their real-life skills.
\end{abstract}

Keywords: Calculus, geogebra, instrumental approach, technology supported mathematics education

\section{GİİŞ}

Matematik eğitiminde teknoloji üzerinde yoğunlaşılan başlıca araştırma konularından biridir (Miles, 2021). Teknoloji kullanımının öğrenmeye pozitif etkisinin oluşturulabilmesi için öğrenme ortamının buna uygun tasarımı ve araç ile matematiksel kavramların ilişkisinin doğru kurgulanması gerektiği belirtilmektedir (NCTM 2015; Van De Walle vd., 2015). GeoGebra, Hohenwarter tarafından bir lisansüstü tezi olarak tasarlanmış, açık kodlu sistemi sayesinde zamanla genişletilmiş bir dinamik geometri yazılımdır (DGY2) (Weinhandl vd., 2020). Özellikle Türkçe dahil farklı dillerde erişime sahip olması, ücretsiz olması, farklı cihazların işletim sistemlerine uyumlu olması ve açık kodlu yapısı itibariyle özel bir yapı kazandırılabilmesi GeoGebra' yı DGY uygulamaları arasında ön plana çıkarmaktadır. Bu itibarla GeoGebra, öğrenen ve öğretenler açısından tercih edilen ve üzerine sıkça araştırma yapılan bir programdır (Birgin ve Acar, 2020; Celen, 2020; Juandi vd., 2021). GeoGebra sayılardan ve şekillerden karşılıklı yararlanma ve şekilleri dinamikleştirme özellikleri ile öğrenenlerin keşfetme süreçlerine rehberlik etmekte, matematiksel düşünmeyi derinleştirme ve zenginleştirme potansiyeline sahip bir uygulamadır (Hohenwarter vd., 2009). GeoGebra sadece cebir ve geometri boyutlarına sahip bir DGY değil aynı zamanda üçüncü boyut oluşturma, olasılıklar

\footnotetext{
${ }^{1}$ Sorumlu Yazar: Dr. Öğretim Üyesi, Isparta Uygulamalı Bilimler Üniversitesi, abdullahozkale@isparta.edu.tr
} 
geliştirme, inşa protokolü sürdürme gibi özellikler ile üniversite düzeyinde de yararlanılabilecek bir bilgisayar destekli cebir sistemi (BCS3) örneğidir (Şekil 1) (Hohenwarter vd., 2009).

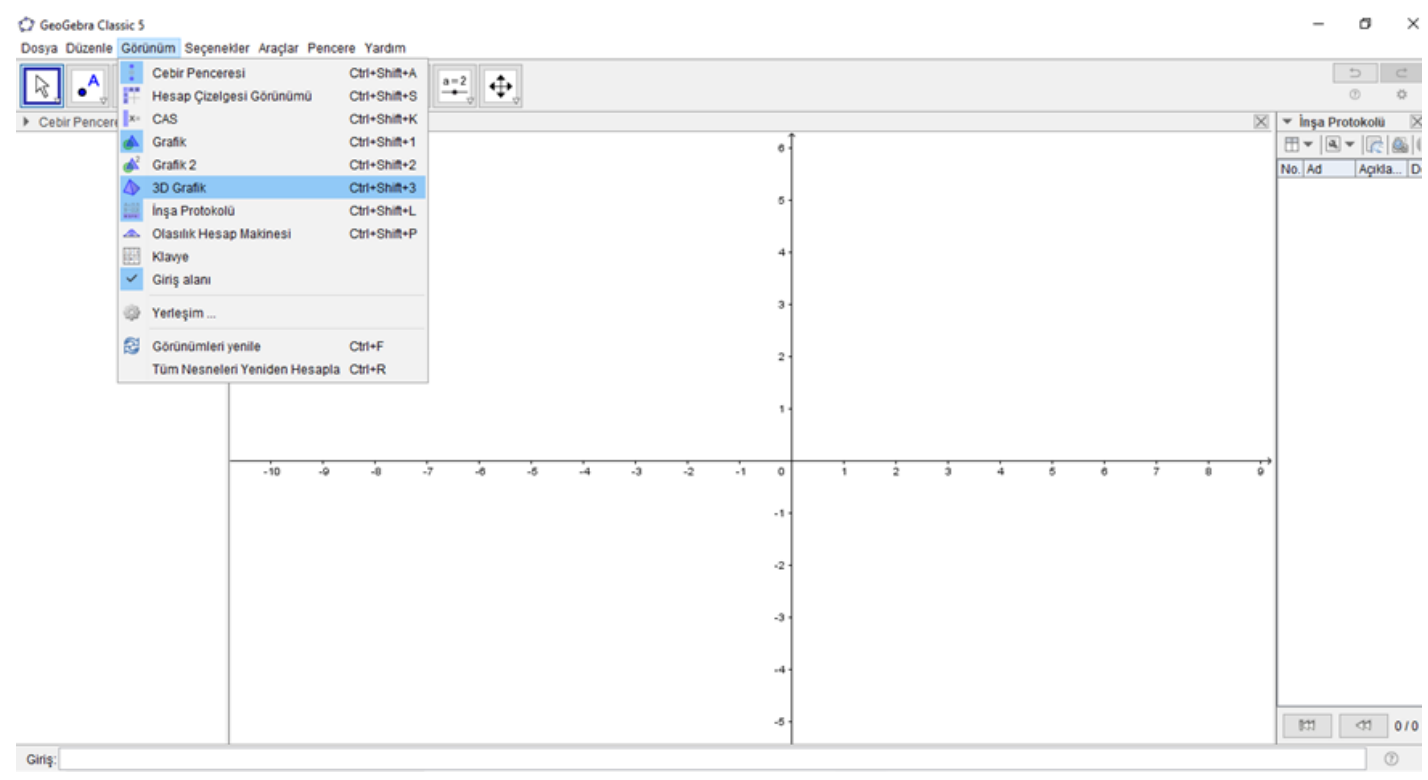

Şekil 1: GeoGebra ara yüzünde çeşitli özelliklerine dair görünüm

Bilgisayar destekli öğretimde (BDÖ) özellikle GeoGebra gibi uygulamaların öğrenme ya da öğretmen süreçlerinde ilgililerin teorik bir rehberliğe ihtiyaç duyduğu görülmektedir (Ainley vd., 2002). Bu itibarla öğrenme süreçlerinin analizinde ve öğretme süreçlerinin organizasyonunda teknoloji destekli öğrenmeye 1şık tutan yaklaşımlar bu sürecin sistematik, öngörülebilir ve sonuçları analiz edilebilir bir yapıya kavuşmasına yardımcı olmaktadır (Haspekian, 2005). Enstrümantal yaklaşım bu teorik temellerinden biridir.

\subsection{Teorik bir temel olarak Enstrümantal Yaklaşım}

Enstrümantal yaklaşım, araç ile öğrenme süreci arasındaki ilişkiyi, öğrenenlerin araç kullanımında geliştirdikleri teknikleri ve kavramsal gelişimlerini inceler (Trouche, 2004). Enstrümantal oluşum bir aracın bir enstrümana dönüşümü olarak kabul edilir. Araç bir görev için kullanılması muhtemel bir materyal ya da soyut yapı iken; enstrüman bu araç yardımıyla öğrenen tarafından geliştirilen öznel bir süreçtir. Şema ise enstrüman haline getirilen araç ile oluşturulmuş çözüm yollarıdır (Drijvers ve Trouche, 2008). Aracın enstrümana dönüştürülmesine katkı sunan kullanım şemalarını ifade eden enstrümantalizasyon ve görevi sırasında oluşan kavramsal şemalara vurgu yapan enstrümantasyon enstrümantal oluşumun iki yönünü ifade eder (Özdemir Erdoğan, 2016). Aracın enstrümana dönüşmesine yol açan şemaların aracın kullanımına yönelik çözüm yolları ve buna dayanak yapılan matematiksel arka planı içermesi beklenir (Özdemir Erdoğan, 2016). Bu şemalar enstrümantalizasyon ve enstrümantasyon süreçleri ile izlenebilir.

Enstrümantal yaklaşımda bilginin teknolojik temellerle sistematik olarak öğretim için hazırlanması ve sürdürülmesi enstrümantal orkestrasyon kavramı ile açıklanmaktadır (Trouche, 2004). Enstrümantal orkestrasyon, aynı ortamdaki birden çok kullanıcının araç-görev-kullanıcılar arasındaki ilişkileri düzenleyen bir çerçevedir. Burada öğreten hem kavramın öğretiminde hem de aracın kullanımında bir rehberdir. Enstrümantal yaklaşımda öğrenme süreçleri çeşitli orkestrasyon türleri ile zenginleştirilmesi hedeflenmiştir (Tablo 1).

$\mathrm{Bu}$ çalışma lisans/önlisans düzeyinde ele alınan kalkülüs dersleri için GeoGebra destekli matematik etkinliklerinin ele alınmasına odaklanmaktadır. Bu itibarla çalışmanın amacı kalkülüs

${ }^{3}$ CAS: Computer Algebra System 
dersleri için hazırlanacak GeoGebra ekinkilerinde öğreticilere yol göstermesi açısından enstrümantal orkestrasyon boyutlarına 1 şı tutan tartışmalar sunmaktadır. Çalışmada kalkülüs eğitimi için GeoGebra programından nasıl yararlanılacağı ve etkinliklerin enstrümantal orkestrasyon türleri ile nasıl zenginleştirilebileceği üzerinde durulmaktadır. Çalışma kapsamında önerilen etkinlikler etkinlik tasarım parametreleri ve enstrümantal orkestrasyon türleri ile birlikte ele alınarak düzenlenmiştir. $\mathrm{Bu}$ çerçevede;

1- Kalkülüs derslerinde GeoGebra programından yararlanılabilecek öğrenme alanları neler olabilir?

2- Kalkülüs öğrenme alanları ile sınırlı tutularak oluşturulan etkinliklerde hangi GeoGebra özellikler işe koşulabilir?

3- İlgili etkinliklerin öğretme süreçlerinde hangi enstrümantal orkestrasyon türlerinden nasıl yararlanılabilir? araştırma sorularına yanıtlar aranmıştır.

\section{2. Üniversite Kalkülüs Eğitimi}

Kalkülüs matematiksel analizlere dayalı, matematiğin uygulama sahalarında etkin rol oynayan bir alt dalıdır (Hass, 2018). Bu yönüyle matematiğe dayalı mühendislik, fizik, kimya, finans ve tıp bilimleri gibi geniş bir yelpazede kalkülüs dersleri verilmektedir. Olasılık, geometri ve cebir gibi matematiğin alt dallarını birlikte ele almaya çalışan kalkülüs, bir ders olarak ele alındığında kazanımların analitik düşünme, matematiksel modelleme, yansıtma ve temsil süreçlerine katkı sunmasının beklendiği görülebilir (http-1; http-2; http-3; http-4).

Üniversitelerde yer alan Kalkülüs derslerine genel olarak bakıldığında ön lisanstan lisansüstü eğitime, verilen mesleki eğitimin ihtiyaçlarına göre çeşitli odaklar oluşturulduğu görülmektedir. Birden farklı kalkülüs kitaplarından yararlanıldığg ifade edilen kalkülüs dersleri için yurtiçinde eğitim veren çeşitli üniversitelerin programları dikkate alındığında ortak öğrenme alanları ve kazanımların tercih edildiği görülmektedir (Adams ve Essex, 2010; Bittinger vd., 2017; Stewart, vd., 2020; Zill, ve Wright, 2011). İlgili dokümanlar detaylı incelendiğinde (a) fonksiyonlar, (b) trigonometri, (c) limit ve süreklilik, (d) türev ve uygulamaları, (e) integral ve uygulamaları, (f) diziler ve seriler ve (g) analitik geometri öğrenme alanlarının ders içeriklerinde yer aldığı görülmektedir (http-1; http-2; http3 ; http-4).

Lisans/önlisans düzeyinde sürdürülen GeoGebra araştırmaları dikkate alındığında fonksiyonlar (Demirbilek ve Özkale, 2014; Zengin, 2017), limit (Kepçeoğlu ve Yavuz, 2017), türev (Zengin ve Tatar, 2014), integral (Sevimli ve Delice, 2016), diziler ve seriler (Ayyıldız, 2020) ve analitik geometri (Baltacı ve Yıldız, 2015) gibi kalkülüsün temel konuları üzerine çalışmalar bulunmaktadır. $\mathrm{Bu}$ araştırmada GeoGebra etkinlikleri temel bir örnek teşkil etmesi açısından fonksiyonlar öğrenme alanında tasarlanmıştır.

\section{YÖNTEM}

$\mathrm{Bu}$ araştırma çerçevesinde GeoGebra programının etkinliklerde ele alınabilmesi için iki temel boyut bulunmaktadır. Bunlar (a) kalkülüs dersinde ele alınan içerikler ve (b) etkinlik tasarımıdır. Kalkülüs derslerine yönelik içerik, öğrenme alanları ve kazanımların ele alınmasında doküman incelemesi gerçekleştirilmiştir. Doküman incelemesi araştırılan konu hakkındaki yazılı ve görsel materyallerin analiz edilmesidir (Yıldırım ve Şimşek, 2008). Bu kapsamda Türkiye'de lisans ve önlisans düzeyinde kalkülüs derslerine sahip üniversitelerin Avrupa Kredi Transfer Sistemi (AKTS) portallarından kalkülüs dersine yönelik bilgilere ulaşılmıştır. Bu dokümanlarda içerik, kazanım ve öğrenme alanlarına yönelik benzer ifadeler üzerinden ortak paydalar oluşturulmaya çalışılmıştır. 
Çalışmanın diğer boyutunda ise etkinliklerin oluşumunda iki temel çerçeveden yararlanılmıştır. Etkinliklerin teknik boyutu etkinlik tasarım parametreleri ile çizilmiştir. Araştırmada etkinliklerin tasarımında yararlanılan parametreler; (a) etkinliğin amacı, (b) uygulama kriterleri (süre, öğretim stratejileri, esneklik vb.), (c) öğrenci ön bilgileri, (d) öğretmen ve öğrenci roller, (e) araçlar, (f) kavram yanılgıları ve zorluklar ile sınırlandırılmıştır (Özmantar ve Bingölbali, 2009; Leung ve Bolite Frant, 2015). Etkinliklerin teorik boyutunda ise enstrümantal yaklaşım çerçevesinde enstrümantal orkestrasyon türlerinden yararlanılmıştır (Tablo 1). Araştırmada fonksiyonlar öğrenme alanında altı (6) farklı etkinlik oluşturulmuştur. Bu etkinlikler bir kalkülüs dersi öğretim elemanı, bir matematik eğitimi anabilim dalı öğretim üyesi ve bir matematik bölümü öğretim üyesi tarafından akran incelemesine tabii tutulmuştur (Merriam ve Grenier, 2019). Etkinliklerin tasarımına yönelik açıklamalar bu iki boyut üzerinden araştırmada ele alınmıştır.

Tablo 1. Enstrümantal orkestrasyon türleri (Drijvers et al., 2010, Trouche \& Drijvers, 2014)

\begin{tabular}{|c|c|}
\hline Orkestrasyon türleri & \\
\hline 1. Teknik-demo & Teknikleri öğretmen gösterir. \\
\hline 2. Ekranı açıkla & $\begin{array}{l}\text { Öğretmen kendi ekranında teknikleri ve matematiksel içerikleri açıklar. Öğretmen } \\
\text { tarafından öğrenci çalışmalarının açıklanması ya da bir etkinlik için kendi } \\
\text { çözümlerinin kullanılarak başlanmasını ifade eder. }\end{array}$ \\
\hline $\begin{array}{l}\text { 3. Ekran ile tahta } \\
\text { arasında bağlantı kur }\end{array}$ & $\begin{array}{l}\text { Bir tahta, ekran ve her ikisinin de görülebilir olduğu bir sınıf oluşumu söz } \\
\text { konusudur. Tekniğe dönük ve matematiksel açıklamalar her ikisinde de } \\
\text { sunulabilir. Süreç öğretmen kontrolünde ilerler. }\end{array}$ \\
\hline 4. Ekranı tartışma & $\begin{array}{l}\text { Ortak enstrümantal oluşum süreçleri geliştirmek için bilgisayar ekranı üzerinde } \\
\text { olanlarla alakalı tüm sınıf tarafından yapılan tartışmalara dayanır. Öğrenenlerin } \\
\text { tartışmalara aktif katılımı gereklidir. }\end{array}$ \\
\hline 5. Yakala ve göster & $\begin{array}{l}\text { Öğrencilerin muhakeme gücüne hitap edecek ilgi çekici durumlar üzerinde } \\
\text { ögrenci çalışmalarının tartışlmasıdır. }\end{array}$ \\
\hline 6. Şerpa öğrenci & $\begin{array}{l}\text { Sınıf içinde seçilen bir öğrenci üzerinden istenen teknik ve kavramsal } \\
\text { açıklamalarının sürdürülmesidir. Burada sınıfın dikkati bir yandan şerpa } \\
\text { öğrencide bir yandan öğretmenin yönlendirmelerindedir. Araç kullanımı } \\
\text { öğretmen yönlendirmeleri eşliğinde şerpa öğrencidedir. }\end{array}$ \\
\hline 7. Çalış ve yürü & $\begin{array}{l}\text { Öğretmen öğrenciler arasında dolaşarak öğrencilerin gelişmelerini ve } \\
\text { davranışlarını izler ve ihtiyaç duyulduğunda öğrencilere rehberlik eder. }\end{array}$ \\
\hline 8. Teknoloji kullanmama & $\begin{array}{l}\text { Sınıf ortamında teknolojinin varlığına karşın öğretmen tarafından tercih } \\
\text { edilmemesidir. }\end{array}$ \\
\hline
\end{tabular}

\section{BULGULAR}

Araştırma kapsamında oluşturulan beş etkinliğin öğrenme alanları ve ele alınan GeoGebra fonksiyonlarına yönelik açıklamalar Tablo 2 de yer almaktadır. Araştırmada bu etkinliklerden Etkinlik 1: Parabol incelemesi' ne yönelik açıklamalar ve görseller bulgulara eklenmiştir.

Tablo 2: Etkinlikler, Ders Öğrenme Alanları ve Planlanan GeoGebra Fonksiyonları

\begin{tabular}{llll}
\hline Etkinlikler & $\begin{array}{l}\text { Öğrenme } \\
\text { alanı }\end{array}$ & $\begin{array}{l}\text { Alt öğrenme } \\
\text { alanı }\end{array}$ & GeoGebra kullanımına yönelik hedefler \\
\hline $\begin{array}{l}\text { Etkinlik 1: } \\
\text { Parabol } \\
\text { incelemesi }\end{array}$ & Fonksiyonlar & $\begin{array}{l}\text { İkinci derece } \\
\text { fonksiyonlar }\end{array}$ & $\begin{array}{l}\text { Parabol elemanlarının, cebirsel ve grafiksel formlarının } \\
\text { değişimlerinin dinamik şekilde incelenmesi }\end{array}$ \\
\hline $\begin{array}{l}\text { Etkinlik 2: } \\
\begin{array}{l}\text { Simetri } \\
\text { incelemesi }\end{array}\end{array}$ & Fonksiyonlar & $\begin{array}{l}\text { Grafiklerde } \\
\text { simetri }\end{array}$ & $\begin{array}{l}\text { Doğruya ve noktaya göre simetri alınmasında \#doğruda } \\
\text { yansit, \#noktada yansit, \#dik doğru, \#orta dikme } \\
\text { fonksiyonlarından yararlanılarak simetri özelliklerinin } \\
\text { incelenmesi }\end{array}$ \\
\hline $\begin{array}{l}\text { Etkinlik 3: } \\
\begin{array}{l}\text { Doğru } \\
\text { grafiğinin } \\
\text { oluşturulması } \\
\text { ve özellikleri }\end{array}\end{array}$ & Fonksiyonlar & $\begin{array}{l}\text { Doğru grafiğinin } \\
\text { çizimi }\end{array}$ & $\begin{array}{l}\text { \#nokta, \#doğru, \#eğim \#kesiştir, \# dik doğru \#paralel doğru } \\
\text { vb. fonksiyonlar üzerinden bir doğrunun çizimi, eğiminin } \\
\text { belirlenmesi, noktalarının isimlendirilmesi ve sonsuz } \\
\text { noktanın takibi ile doğruların birbirine göre durumlarının } \\
\text { incelenmesi }\end{array}$ \\
\hline
\end{tabular}




\begin{tabular}{|c|c|c|c|}
\hline $\begin{array}{l}\text { Etkinlik 4: } \\
\text { Asimptot } \\
\text { incelemesi }\end{array}$ & Fonksiyonlar & $\begin{array}{l}\text { Rasyonel } \\
\text { fonksiyonlar }\end{array}$ & $\begin{array}{l}\text { Başta \#kesiştir fonksiyonu kullanılarak asimptotların ve } \\
\text { buna bağlı olarak tanım aralıklarının incelenmesi }\end{array}$ \\
\hline $\begin{array}{l}\text { Etkinlik 5: } \\
\text { Üstel ve } \\
\text { logaritmik } \\
\text { fonksiyonların } \\
\text { birlikte } \\
\text { incelenmesi }\end{array}$ & Fonksiyonlar & $\begin{array}{l}\text { Üstel-logaritmik } \\
\text { fonksiyonlar }\end{array}$ & $\begin{array}{l}\text { \#uç nokta ve diğer iki grafiğin ve noktanın birbirine göre } \\
\text { durumlarında yararlanılan fonksiyonlar üzerinden üstel ve } \\
\text { logaritma fonksiyonun birbirine göre fonksiyon } \\
\text { özelliklerinin incelenmesi, buna bağlı olarak ters fonksiyon } \\
\text { özelliklerinin incelenmesi }\end{array}$ \\
\hline $\begin{array}{l}\text { Etkinlik 6: } \\
\text { Trigonometrik } \\
\text { fonksiyon } \\
\text { grafikleri ve } \\
\text { periyotlar }\end{array}$ & Fonksiyonlar & $\begin{array}{l}\text { Trigonometrik } \\
\text { fonksiyonlar }\end{array}$ & $\begin{array}{l}\text { \#uç nokta \#kökler ve \#kesiştir fonksiyonları ile trigonometrik } \\
\text { fonksiyonların konumları ve extremum değerlerinin, } \\
\text { periyotlarının, tanım aralıklarının ve birbirleri ile ilişkilerinin } \\
\text { incelenmesi }\end{array}$ \\
\hline
\end{tabular}

\section{Etkinlik 1: Parabol incelemesi}

İkinci dereceden fonksiyonların grafikleri olan parabollerin tepe noktası (extremum değer), eksenleri kesen noktalar, kollarının yönü gibi incelenebilecek çeşitli noktaları bulunmaktadır. GeoGebra üzerinde bu incelemenin konu alındığı Etkinlik 1' de \#taşı, \#uç nokta, \#kökler \#nokta, \#parabol fonksiyonları üzerinden bir öğrenme süreci tasarlanmıştır. Buna göre ilk olarak öğreten *teknik-demo yöntemiyle fonksiyonların kullanımını parabol kavramı çerçevesinde gerçekleştirir. Öğrenenlerin deneyimleme sürecinde ise *ekran tartışma ve *yakala ve göster yöntemleri üzerinden ortak enstrümantal süreçlerin geliştirilmesi ve extremum değer-eksenleri kesen noktalar gibi parabol elemanlarının keşifleri birlikte tartış1lır. Yine öğrenenlerin kendi bilgisayarlarında yürüttüğü etkinlik süreçlerinin takibi için öğreten *çalış ve yürü yöntemini kullanır.

Etkinlik 1 in içerisinde GeoGebra' nın kavramsal ve teknik özelliklerine bağlı olarak çok sayıda süreç olasılığı oluşturulabilir. Öğrenenlerin parabol elemanlarının değişimlerinin izlemelerine yönelik bir uygulama Şekil 2 de gösterilmiştir. Bu uygulamada öncelikle ikinci dereceden denklemin katsayıları GeoGebra' da \#sürgü fonksiyonu ile dinamikleştirilmesi, ardından $f(x)=a x^{2}+b x+c$ fonksiyonu oluşturtularak sürgülerin değişiminde parabolün nasıl değiştiğine yönelik incelemeler ve buna dair tartışmalar yapılması istenmektedir. $\mathrm{Bu}$ inceleme fonksiyonun katsayıları belirlenerek direkt cebir giriş ekranından da yapılabilir. Ancak değişimlerin anlık ve hızlı şekilde yapılabilmesi ve görülebilmesi için sürgü kullanımı ön plana alınmıştır.

Yaklaşık 20 dakika olarak tasarlanan Etkinlik 1' de öğrenenlerin özellikle birinci dereceden fonksiyon grafiklerinin çiziminde elde ettikleri deneyimleri GeoGebra üzerinde ikinci dereceden fonksiyon grafiklerine aktarmaları istenmektedir. Öğreten ilgili fonksiyonların kullanımı için bir rehber aynı zamanda öğrenenlerinin deneyimlerini inceleyen bir gözlemcidir. Etkinliğin amacı başlangıçta "parabol elemanlarının GeoGebra üzerinde keşfi”" olarak belirtilmesi istenmektedir. Etkinlik 1 için hazırlanmış yönerge Tablo 3' de gösterilmiştir. 


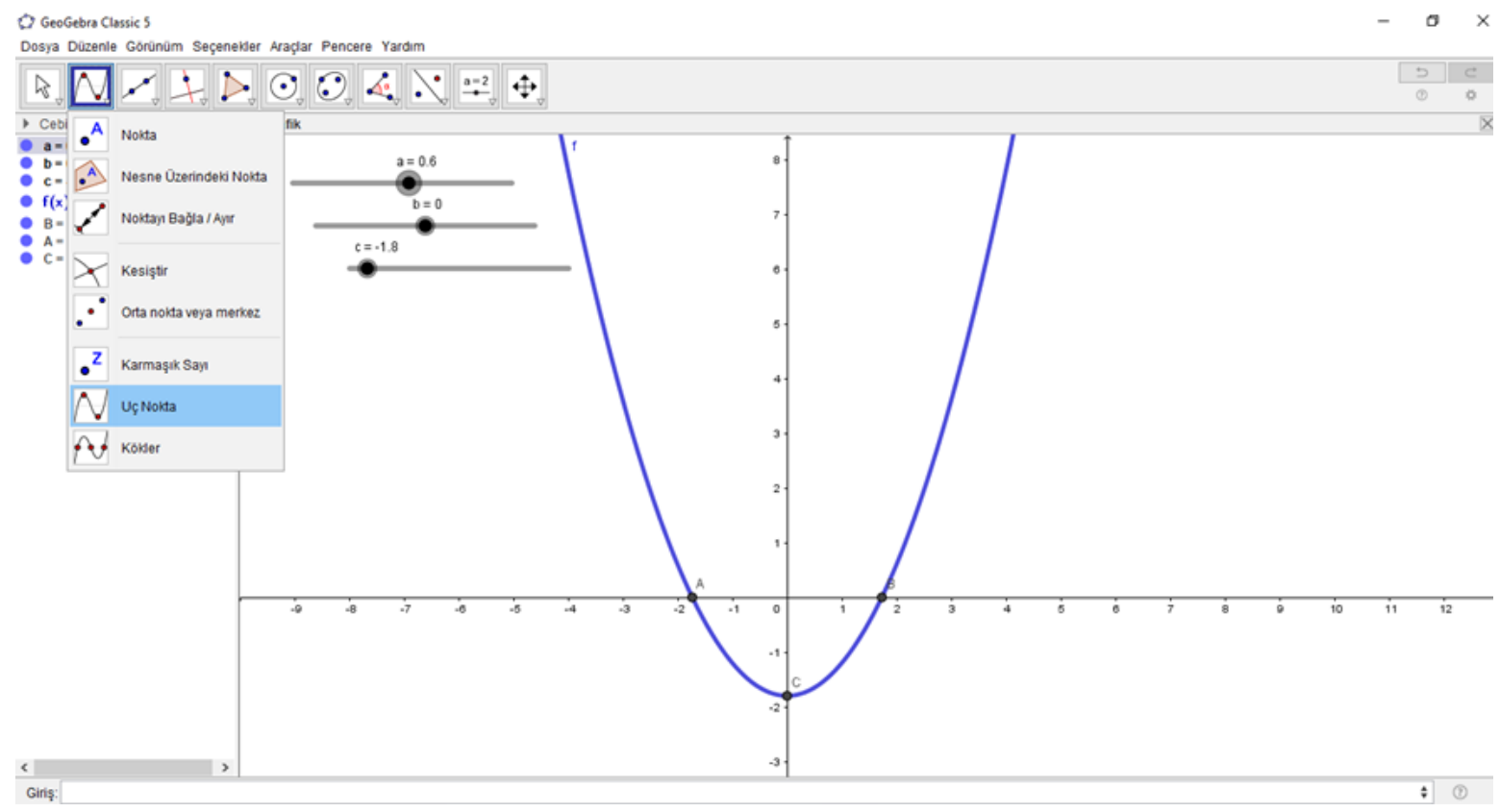

Şekil 2: Parabolün değişiminin GeoGebra’ da dinamikleştirilmesinin incelemesi

Tablo 3. Etkinlik 1 için hazırlanmış ders yönergesi

\begin{tabular}{|c|c|}
\hline \multicolumn{2}{|c|}{ Etkinlik 1: Parabol incelemesi } \\
\hline Kalkülüs 1 - MAT-151 & Etkinliğin amacı: Parabol elemanlarının GeoGebra üzerinde keşfi \\
\hline $\begin{array}{l}\text { Enstrümantal } \\
\text { orkestrasyon adımları }\end{array}$ & $\begin{array}{l}\text { Uygulama adımları } \\
\text { - Kendi bilgisayarınızda GeoGebra ekranının açınız ve öğrenenler tarafından } \\
\text { görülecek şekilde ayarlayınız. Öğrenenlerin kullandıkları araçlarda Geogebra } \\
\text { programının çalışır vaziyette olup olmadığını kontrol ediniz. }\end{array}$ \\
\hline *teknik-demo & $\begin{array}{l}\text { - \#taşı, \#uç nokta, \#kökler \#nokta, \#parabol fonksiyonlarının kullanımını } \\
\text { öncelikle kendi bilgisayarınızda yaparak öğrenenlere gösterininiz, programın } \\
\text { kullanımına yönelik açıklamalarda bulununuz. }\end{array}$ \\
\hline $\begin{array}{l}\text { *çallş ve yürü } \\
\text { *ekran tartışma }\end{array}$ & $\begin{array}{l}\text { - Her bir fonksiyonun uygulanmasında öğrenenlerin kendi araçlarındaki } \\
\text { süreçlerini aralarında dolaşarak gözlemleyiniz, gereken noktalarda yardımcı } \\
\text { olunuz, keşfetmelerine 1şı tutacak ipuçları vererek uygulamaları tartışınız. }\end{array}$ \\
\hline & Kavramsal notlar \\
\hline *ekran tartışma & $\begin{array}{l}\text { ! Tepe noktası-extremum nokta kavramı ve extremum değer arasındaki ilişkiyi ve } \\
\text { farklılıkları göz önünde bulundurarak öğrenenlerin bu yöndeki kavram } \\
\text { yanılgılarını gideriniz. }\end{array}$ \\
\hline & $\begin{array}{l}\text { ! Eksenleri kesen noktaların fonksiyonların cebirsel formlarına göre durumlarını } \\
\text { tartışınız. }\end{array}$ \\
\hline $\begin{array}{l}\text { *yakala ve goster } \\
\text { *ekran tartışma }\end{array}$ & $\begin{array}{l}\text { *yakala ve göster yöntemiyle fark edilmesi gereken durumları teker teker teker } \\
\text { öğrencilerle birlikte inceleyiniz, uygulayını. }\end{array}$ \\
\hline *şerpa ögrenci & $\begin{array}{l}\text { ! Grafiğin daralma ve genişleme durumları ile kollarının yönünün cebirsel } \\
\text { formdaki karşılıklarını uygulayarak öğrencilerle birlikte tartışınız. }\end{array}$ \\
\hline & $\begin{array}{l}\text { ! Öğrencilerin grafiksel ya da cebirsel modellemelerde farklı çözümler } \\
\text { üretmelerine firsat tanıyınız, bu modelleri sınıf ortamında *şerpa ögrenci } \\
\text { yöntemiyle sürdürünüz. }\end{array}$ \\
\hline
\end{tabular}

\section{SONUÇ VE TARTIŞMA}

$\mathrm{Bu}$ çalışmada oluşturulan sınırlı sayıdaki kalkülüs etkinlikleri lisans/önlisans düzeyinde GeoGebra kullanımının yaygınlaştırılmasına yönelik bir çabanın ürünüdür. Bu etkinliklerin temel hedeflerinden biri de öğrenen ve öğretenler açısından sınıf ortamına teknoloji destekli etkinliklerin taşınması, bununla birlikte bireysel çalışmalarında GeoGebra' dan yararlanmalarına 1şık tutmaktır. 
Literatürde var olan ilgili düzeydeki çalışmalarda DGY ya da BCS üzerine oluşturulan etkinliklerin keşif üzerinden ispatlama odaklı yapılarının kavramsal anlamayı ön plana alana aldığı görülmektedir (Baltacı ve Yıldız, 2015; Sevimli ve Delice, 2016; Zengin ve Tatar, 2014). Kalkülüs gibi uygulama odaklı derslerde ise verilen geçek hayat probleminin çözümünde yararlanılacak, cebirsel ve grafiksel modeller arasında ilişkilendirme kurulmasına yardımcı olacak etkinliklerin daha yararlı olacağı düşünülmektedir. Bu itibarla etkinlikler fonksiyonların farklı alt öğrenme alanlarına yoğunlaşarak ders içeriklerine uygun temel öğrenme çıktıları/hedefleri üzerinde durmuştur.

Etkinliklere yön veren teorik altyapı olan Enstrümantal yaklaşıma göre etkinliklerin GeoGebra' y1 ve her bir fonksiyonu bir araçtan kişiye özgü bir enstrümana dönüştürme gayreti söz konusu olmalıdır (Özdemir Erdoğan, 2016). Bu süreçte öğrencilerin geliştirdikleri kullanım şemaları ve kavramsal şemalar ise enstrümantal oluşumun derinliğini belirleyecektir. Bu itibarla öğrenenlerin teknolojiye ya da GeoGebra programına yakınlığı/alışkanlığı diğer taraftan matematiksel altyapısı ve ön bilgileri bu oluşumunda rol oynayacaktır. Literatüre bakıldığında öğrencilerin bir aracı enstrümana dönüştürme süreçlerinde teknoloji kullanımını geliştirmelerine karşın kavramsal gelişimlerinde ilerleme kaydedilmediği görülmektedir (Miles, 2021). Bu nedenle teknoloji destekli öğrenme süreçlerinde öğrenenlerin kullanılan araca olan motivasyonunun ve becerisinin kavramsal gelişime yansıtılması bu tarz çalışmalarda önem arz etmektedir. Etkinliklere yön veren enstrümantal orkestrasyon türlerinin bu çerçevede tercih edildiği ifade edilebilir.

Özellikle COVID-19 döneminde sınıf ortamına ulaşamayan öğrencilerin derslerini online takip etmelerinin yanında ilgili kaynaklara da yine web portalları üzerinden ulaştıkları göz önüne alındığında benzer etkinliklerin bu medya olanaklarına uygun şeklide hazırlanmasının öğrenen ve öğretenlerin ulaşımı açısından bir avantaj oluşturacağı düşünülmektedir. Oluşturulacak etkinliklerde ilgili kazanımlar, öğrenci ön bilgileri gibi parametrelerinin yanında araç üzerinde kullanıcı rollerini açıç̧a ifade eden, onların kavramsal gelişimlerini ilerletmeyi hedefleyen ve muhtemel kavram yanılgılarını dikkate alan tasarımlar için gayret gösterilmesi sistematik bir etkinlik organizasyonu açısından değerli görülmektedir. COVID-19 Pandemisi sonrası öğrenenlerin okul ortamına entegrasyonu ve motivasyonu açısından teknoloji odaklı ders süreçleri yararlı olabilir. Bu itibarla benzer etkinliklerin farklı disiplinler için de değerlendirilebileceği düşünülmektedir.

\section{KAYNAKÇA}

[1] Adams R.A. \& Essex, C. (2010). Calculus, Pearson.

[2] Ainley, J., Banks, D., \& Fleming, M. (2002). The influence of IT: Perspectives from five Australian schools. Journal of computer assisted learning, 18(4), 395-404.Bransford, J. D., Brown, A. L. ve Cocking, R. R. (2000). How people learn: Brain, mind experience, and school. Washington, DC: National Academy Press. [3] Ayyıldız, A. (2020). Geogebra destekli öğretimin ilköğretim matematik öğretmeni adaylarının akademik performanslarına ve motivasyonlarına etkisi: Diziler örneği. Necmettin Erbakan Üniversitesi Ereğli Eğitim Fakültesi Dergisi, 2(2), 152-174.

[4] Baltacı, S., \& Yıldız, A. (2015). Matematik Öğretmen Adaylarının Geogebra Yazılımı Yardımıyla Analitik Geometrideki Bir Konuyu Öğrenme Süreçleri. Ahi Evran Üniversitesi Kırşehir Eğitim Fakültesi Dergisi,16(3), 295-312.

[5] Birgin, O., \& Acar, H. (2020). The effect of computer-supported collaborative learning using GeoGebra software on 11th grade students' mathematics achievement in exponential and logarithmic functions. International Journal of Mathematical Education in Science and Technology, 1-18.

[6] Bittinger, M. L., Beecher, J. A., Ellenbogen D.J., Penna, J.A. (2017). Kalkülüse Giriş: Grafiker ve Modeller (Çev. Ed. Civan, Y.) Ankara: Nobel Yayınevi.

[7] Celen, Y. (2020). Student Opinions on the Use of Geogebra Software in Mathematics Teaching. Turkish Online Journal of Educational Technology-TOJET, 19(4), 84-88.

[8] Demirbilek, M., \& Özkale, A. (2014). GeoGebra kullanımının önlisans matematik öğretimine etkinliğinin incelenmesi. Necatibey Eğitim Fakültesi Elektronik Fen ve Matematik Eğitimi Dergisi, 8(2), 98123. 
[9] Haspekian, M. (2005). An "instrumental approach" to study the integration of a computer tool into mathematics teaching: the case of spreadsheets. International journal of computers for mathematical learning, 10(2), 109-141.

[10] Hohenwarter, M., Jarvis, D., \& Lavicza, Z. (2009). Linking Geometry, Algebra, and Mathematics Teachers: GeoGebra Software and the Establishment of the International GeoGebra Institute. International Journal for Technology in Mathematics Education, 16(2).

[11] Hass, J. (2018). Thomas' calculus. Pearson.

[12] Juandi, D., Kusumah, Y. S., Tamur, M., Perbowo, K. S., \& Wijaya, T. T. (2021). A meta-analysis of Geogebra software decade of assisted mathematics learning: what to learn and where to go?. Heliyon,7(5).

[13] Kepçeoğlu, İ., \& Yavuz, İ. (2017). The Effect of GeoGebra on Achievement of Preservice Mathematics Teachers About Concepts of Limit and Continuity. Necatibey Faculty of Education Electronic Journal of Science \& Mathematics Education, 11(1).

[14] Leung, A. \& Bolite Frant, J. (2015). Designing mathematics tasks: The role of tools In A. Watson \& M.Ohtani (eds.) Task design in mathematics education. 191-227. NY: Springer .

[15] Merriam, S. B. ve Grenier, R. S. (2019). Qualitative research in practice: Examples for discussion and analysis. CA: John Wiley \& Sons.

[16] Miles, R. (2021). An alternative route to the Mandelbrot set: connecting idiosyncratic digital representations for undergraduates. Teaching Mathematics and its Applications: An International Journal of the IMA, 40(1), 72-82.

[17] Ozmantar, M.F. ve Bingolbali, E. (2009). Etkinlik tasarımı ve temel tasarım prensipleri. In Bingolbali, E., Ozmantar, M.F. (Ed), Ilkoğretimde Karşılaşılan Matematiksel Zorluklar ve Çözüm Önerileri. Ankara: Pegem Akademi.

[18] Stewart, J., Clegg, D. K., \& Watson, S. (2020). Calculus: early transcendentals. MA: Cengage Learning.

[19] Sevimli, E., \& Delice, A. (2016). Bilgisayar cebir sistemi destekli öğretimin kavramsal-işlemsel yeterliklere etkisinin incelenmesi: integral örneği. Hacettepe Üniversitesi Eğitim Fakültesi Dergisi, 31(2), 117.

[20] Weinhandl, R., Lavicza, Z., Hohenwarter, M., \& Schallert, S. (2020). Enhancing flipped mathematics education by utilising GeoGebra. International Journal of Education in Mathematics, Science and Technology, $8(1), 1-15$.

[21] Yıldırım, A. ve Şimşek, H. (2008). Sosyal bilimlerde nitel araştırma yöntemleri (9. Baskı). Ankara: Seçkin Yayınc1lık.

[22] Zengin, Y. (2017). Komşuluk ve Yığılma Noktası Kavramlarının Dinamik Matematik Ortamında Keşfedilmesi Üzerine Bir Araştırma. Mehmet Akif Ersoy Üniversitesi Eğitim Fakültesi Dergisi, (43), 302-333.

[23] Zengin, Y., \& Tatar, E. (2014). Türev Uygulamaları Konusunun Öğretiminde Geogebra Yazılımının Kullanımı. Kastamonu Eğitim Dergisi, 22(3), 1209-1228.

[24] Zill, D., \& Wright, W. S. (2011). Calculus: Early Transcendentals. MA: Jones \& Bartlett Learning.

[25] http-1. https://www.atilim.edu.tr/tr/ects/site-courses/201/12131/detail

[26] http-2.https://www.anadolu.edu.tr/akademik/fakulteler/ders/82509/calculus-ii-genel-matematik-

ii/ders-icerik

[27] http-3.https://obs.sdu.edu.tr/Public/EctsCourseDetails.aspx?DersNo=130400181160510200\&Bolum $\mathrm{No}=5102 \&$ BirimNo $=51 \&$ DersBolumKod $=$ MAT -181

[28] http-4. https://fenedebiyat.yeditepe.edu.tr/tr/fizik-matematik/dersler/173 